\section{Usos da noção de subjetividade no campo da Saúde Coletiva}

\author{
Uses of the concept of subjectivity \\ in Public Health
}

\author{
1 Pontificia Universidade \\ Católica de Minas Gerais, \\ Belo Horizonte, Brasil. \\ Correspondência \\ J. L. Ferreira Neto \\ Pontifícia Universidade \\ Católica de Minas Gerais. \\ Av. Itaú 525, Belo Horizonte, \\ MG 30535-012, Brasil. \\ jleite.bhe@terra.com.br
}

\section{Abstract}

This article analyzes the use of the concept of subjectivity in the public health field, associated with the historical and institutional conditions that demanded it. The main methodological strategy was a search in specific journals and reference books from the field. We identified three functions in the use of the concept of subjectivity, associating them primarily with external variables (trajectory in the health movement and institutionalization of the Unified National Health System - SUS) and secondarily with internal variables (logic of the theoretical/conceptual field). The functions discuss subjectivity as: (1) an element for conceiving the social action by political actors in the Health Reform project; (2) a strategy for problematizing health care and management as inter-subjective practices; and (3) a substrate for the production of autonomy for individuals and collectives. In their external variables, the three functions are established as processes for building micro and macro policies for the consolidation of the SUS.

Scientific Domains; Public Health; Unified Health System; Review
João Leite Ferreira Neto 1

Luciana Kind 1

Alessandra Barbosa Pereira 1

Maria Carolina Costa Rezende 1

Marina Lanari Fernandes 1

\section{Introdução}

Este estudo consolida um primeiro eixo da pesquisa Promoção da Saúde e Processos de Subjetivação, cujo foco é estudar os usos da noção de subjetividade e noções correlatas na literatura, nos documentos governamentais e nas práticas de promoção da saúde, mediante estudos de caso de usuários "participativos". Nessa primeira etapa trabalhamos o uso da noção de subjetividade e seus correlatos na literatura sobre Saúde Coletiva e Promoção da Saúde. O pressuposto é que a discussão acadêmica se constitui como um dos elementos que compõem as diretrizes das políticas públicas, tornando-se assim um prérequisito importante na análise dos documentos governamentais sobre promoção da saúde, o que será feito em outra etapa.

A tematização da subjetividade e noções a ela associadas na Saúde Coletiva segue diferentes inspirações teóricas, de fundo marxista, sociológico, hermenêutico, psicanalítico, pós-estruturalista, entre outros. Em geral, sua utilização não é marcada por uma extrema fidelidade ao campo teórico de origem, mas visa atender a questões emergentes do processo de construção e consolidação do Sistema Único de Saúde (SUS). Por vezes, são compostos híbridos de distintas orientações teóricas, marca do movimento sanitário com sua direção transdisciplinar, desde suas primeiras produções, como a 
tese de doutorado de Sergio Arouca de 1975, que associava o materialismo histórico à arqueologia de Michel Foucault 1.

Nosso estudo, na etapa exposta neste artigo, tece uma análise histórico-conceitual, resgatando a associação entre o uso da noção de subjetividade e a emergência de condições históricas e institucionais que o demandaram. Trata-se de evidenciar a conexão entre o domínio conceitual e o domínio social 2.

Entendemos que um conceito surge como resposta a problemas que se apresentam em determinadas áreas, sendo sua gênese, portanto, sempre local e regional 3 . O mesmo ponto de vista pode ser estendido à frequente transposição de conceitos para áreas que anteriormente não os utilizavam. Esse é o caso da noção de subjetividade, oriunda do âmbito das ciências humanas, adentrando na área da Saúde Coletiva.

\section{Metodologia}

Um conceito cumpre uma ou mais funções em um campo de pensamento. Sua relação com esse campo é definida por variáveis internas e "variáveis externas (estados de coisas, momentos da história) em uma relação complexa com as variáveis internas e as funções” 4 (p. 326). Este será o eixo analítico central deste trabalho: enfatizar quais funções o conceito possui no campo problemático que o construiu e quais variáveis externas estão a ele associadas. Deixaremos em um plano secundário a análise da lógica interna, epistemológica, da utilização do conceito. Assim, nossas análises privilegiam a identificação de funções do uso do conceito, associando-as primariamente às suas variáveis externas (trajetória do movimento sanitário e institucionalização do SUS), e, secundariamente, trazendo alguns apontamentos sobre as variáveis internas (caracterização do campo teórico-conceitual, lógica e direção sistemática desse campo).

Em uma discussão feita com Michel Foucault, Deleuze afirma que toda teoria é local, relativa a um pequeno domínio, mas que se pode aplicar a outro mais afastado, numa relação que nunca é de semelhança. Pelos obstáculos encontrados em certo domínio é produzido um movimento de revezamento entre uma teoria e outra e entre uma prática e outra. "Nenhuma teoria pode se desenvolver sem encontrar uma espécie de muro e é preciso a prática para atravessar o muro" 3 ( $\mathrm{p}$. 70). Disso advém a ideia da teoria como caixa de ferramentas, que deve funcionar em um campo de práticas e não em função de si mesma. Podemos pensar dessa maneira a utilização do conceito de subjetividade, próprio das ciências humanas, na Saúde Coletiva. Em face de certos "muros" encontrados na ação do movimento sanitário, foi preciso operar revezamentos para fazer funcionar determinadas práticas em saúde, fosse de construção do próprio sistema de saúde, fosse de desenvolvimento da ação assistencial, ou de diretriz política do trabalho, conforme veremos adiante.

Na construção do corpus da pesquisa, optouse por pesquisar artigos disponíveis na base de dados SciELO, utilizando-se do cruzamento entre a palavra-chave "saúde" e os descritores "sujeito”, “subjetividade”, "subjetivação”, “autonomia” e "promoção da saúde". Os últimos dois descritores foram incluídos em função da temática organizadora da pesquisa - exposta anteriormente - ser a relação entre Promoção da Saúde e processos de subjetivação. Produziuse assim, uma lista de artigos para cada busca cruzada das palavras-chave mencionadas. Leituras exploratórias permitiram a seleção de 13 artigos da área da Saúde Coletiva, publicados até 2009, sobre os quais nos debruçamos de modo a analisar as funções e variáveis externas envolvidas no uso da noção de subjetividade. Tal momento de coleta de dados constitui um núcleo de artigos em publicações qualificadas, a partir do qual outros textos neles referenciados foram selecionados. Construiu-se, assim, uma rede de publicações sobre as quais leituras interpretativas permitiram a produção das análises que aqui apresentamos.

Nesse processo, como critérios de seleção dos textos encontrados, optou-se pela exclusão dos artigos que realizam a discussão da subjetividade dentro do campo específico da saúde mental e dos que utilizavam o descritor "sujeito" como sinônimo de indivíduo, sem desenvolver uma reflexão conceitual sobre ele.

Paralelamente, foram feitas leituras em artigos afins, que mesmo não tendo o tema subjetividade como foco maior, apresentavam contribuições que consideramos significativas à discussão sobre subjetividade e Saúde Coletiva. Trabalhos publicados como livro ou capítulo de livro dos autores mais referidos nos artigos localizados nas buscas na SciELO também foram alvo de nossa leitura e análise. Artigos publicados após o primeiro semestre de 2009 foram sendo paulatinamente incluídos até o primeiro semestre de 2010, quando concluímos essa etapa da pesquisa. A inclusão de material bibliográfico durante o desenvolvimento da investigação respeitou os critérios de busca na base de dados SciELO exposto anteriormente.

O curso das buscas, seleções e novas inclusões de textos ao longo do trabalho comporta uma compreensão da pesquisa qualitativa 
coincidente com o exposto por Minayo ${ }^{5}$ (p. 23), que vê a pesquisa como "uma atitude e uma prática teórica de constante busca que define um processo intrinsecamente inacabado e permanente". Deste modo, os passos de produção de dados foram alvo constante de nossas preocupações, mas nossas buscas e análises certamente não esgotam o tema em estudo.

A análise desse material se deu como processo de trabalho da equipe de pesquisa, por meio de discussões nas reuniões periódicas e, posteriormente, no contexto de uma disciplina ofertada pelo coordenador da pesquisa no Programa de Pós-graduação em Psicologia da Pontifícia Universidade Católica de Minas Gerais (PUC Minas), intitulada Saúde Coletiva e Subjetividade, no segundo semestre de 2009. Na medida em que pesquisar envolve "o compartilhamento de um território existencial” em que "sujeito e objeto se relacionam e se codeterminam" 6 (p. 131), um estudo conceitual necessita produzir modalidades de habitação intensificada entre pesquisadores e textos, especialmente porque nosso universo de trabalho acadêmico atual está caracterizado por múltiplas e fragmentadas tarefas. A associação entre as atividades de reuniões de pesquisa e de docência por intermédio da disciplina que discutia a própria pesquisa mostrou-se ser uma estratégia metodológica interessante ao criar espaços de intensificação reflexiva em torno dos textos e conceitos.

Entendemos que uma investigação deve combinar um respeito pelo corpus com o qual se trabalha, com uma disponibilidade inventiva que se oferece ao encontro de elementos relevantes, de pontos nodais do material estudado, que nem sempre estão disponíveis automaticamente aos procedimentos formais de análise de dados. Logo, fomos delineando funções, tomadas como linhas interpretativas, tecendo permanentemente a relação do debate conceitual com a trajetória do movimento de construção e consolidação do SUS. Privilegiou-se o eixo analítico já mencionado: a localização das funções e das variáveis externas e internas a elas associadas, relativas ao uso da noção de subjetividade na literatura do campo da Saúde Coletiva. É com base nessas funções e suas variáveis que apresentaremos a análise dos textos.

Entendemos que os enunciados discursivos em torno da noção de subjetividade encontrados nessa revisão bibliográfica possuem um regime de materialidade institucional e, por isso, sua análise deve ir além da exegese textual, incluindo também as condições socioinstitucionais, o regime de verdade de sua produção 7 .

\section{Primeira função: construção política de atores sociais para a reforma sanitária}

Não existe um consenso na definição da Saúde Coletiva, mas podemos pensá-la tanto como um campo de conhecimento e de práticas, quanto como um movimento de base acadêmica, associado à reforma sanitária ${ }^{8}$. Em seu início, no decorrer da década de 1970, teve como marca principal a incorporação da dimensão social ao pensamento sanitário, valendo-se da tradição marxista, visando assim superar o modelo exclusivamente biologicista, na direção de uma compreensão da saúde que contemple seus determinantes sociais. Por essa razão, na visão de um de seus componentes, "tendeu a subestimar a importância dos sujeitos na construção do cotidiano e da vida institucional" 8 (p. 222).

A entrada da noção de subjetividade no campo da Saúde Coletiva deu-se, portanto, tardiamente. Apenas nos anos 1990, a subjetividade, como questão conceitual, "entra na pauta das argumentações de alguns autores" 9 (p. 576). Minayo 10 (p. 15) afirma, nessa direção: "[a] década de 1990 pode ser considerada a do 'retorno do sujeito' como necessário, como ator das reformas, como partícipe, para empreendê-las ou para desviá-las". No entanto, é na década seguinte que localizamos o maior número de publicações.

Há um consenso entre diversos autores que, se o movimento da reforma sanitária, em seu nascimento, era influenciado amplamente por um marxismo que objetivava mudanças estruturais, para garantir seu avanço era necessário o aporte de outras contribuições das ciências humanas, sendo uma delas o conceito de sujeito 11,12,13,14. A maioria desses autores se contrapõe à tendência de determinismo estrutural presente nas discussões marxistas da época, à noção de sujeito como agente de mudanças, como indica o título de um dos artigos que abordam o tema: Estrutura e Sujeito, Determinismo e Protagonismo Histórico 13. Ou seja, o sujeito, em seu protagonismo, é a contraposição à estrutura e ao determinismo. Esta se constitui como a primeira função da noção de sujeito na Saúde Coletiva.

Evidentemente, mesmo sendo prevalente, essa interpretação não é consensual entre outros autores. Alguns que se mantêm mais arraigados à tradição marxista insistem que "o marxismo, desde o 18 de Brumário e as lutas sociais na França não se reduz ao componente da estrutura, nem subestima a subjetividade" 15 (p. 41). Como contraponto a tal perspectiva, apenas salientamos o fato de o princípio metodológico de nossa análise privilegiar as funções e variáveis externas em momentos históricos, evitando uma discussão epistemológica se tal ponto está ou não presente 
na obra do autor que serviu de inspiração à discussão desenvolvida. Interessa-nos antes perguntar quais variáveis externas, circunstâncias históricas, demandaram a aproximação desse conceito ao campo da Saúde Coletiva e a que problemas seu uso busca responder.

O periódico Ciência \& Saúde Coletiva abriu seu primeiro número do século XXI dedicado à temática da subjetividade no campo da saúde, na esteira do VI Congresso Brasileiro de Saúde Coletiva, que abordou o tema O Sujeito na Saúde Coletiva. O Editorial já aponta que a relevância do tema na saúde não é proporcional ao debate até então realizado. Aponta-se que "tudo ainda é bastante tangencial porque sujeito e subjetividade ainda não são assunto relevante para a racionalidade hegemônica da área" 10 (p. 4).

Observa-se que a primeira função da noção de sujeito na Saúde Coletiva designa o processo coletivo de transformação social, da ação social de sujeitos políticos que formulam e produzem o projeto da Reforma Sanitária. Aqui se faz presente a influência do marxismo italiano, com referências à Gramsci e Berlinger, através de noções como "subjetividade histórica de um grupo social" e de "consciência sanitária” 16,17. Posteriormente, mas nessa mesma direção, agregou-se a teoria da ação social de Alain Touraine e suas categorias de ator/sujeito social 18.

A variável externa que preside essa primeira função da noção de sujeito é a própria trajetória do movimento sanitário na construção do SUS. Sua dimensão de movimento social determina esse importante foco dos debates e, ao mesmo tempo, indica os limites da discussão possível em torno da subjetividade naquele momento. Segundo Carvalho 17 (p. 111), “a subjetividade aqui admitida é aquela que brota da necessidade coletiva e se organiza em sujeitos coletivos portadores de projetos políticos de intervenção/interação nas estruturas que moldam socialmente as realidades sanitárias".

Para esta primeira função, dentro do campo de pensamento que foca os processos coletivos numa perspectiva política, os autores ligados ao materialismo histórico se mostraram como referências importantes. Particularmente, destacase a obra de Gramsci, com um marxismo menos atrelado ao determinismo infraestrutural econômico, que resgata a importância da superestrutura e analisa instrumentos para a construção de contra-hegemonias, constitui-se como variável interna apropriada para sustentar essas discussões. Era necessária uma perspectiva teórica que permitisse ao movimento sanitário afirmar-se como processo de reforma social relevante, mesmo que seu alcance a aproximasse mais de uma reforma parcial, apontando "as possibilidades para a ação social" e para a construção de um coletivo engajado na mudança 15.

Um dos textos inaugurais dessa primeira função, publicado em 1992, assinala a necessidade de valorização dos “processos de produção de sujeitos sociais" 11. Subjetividade, assim, é apresentada como uma noção importante para se fazer avançar a reforma sanitária, especialmente seus dois atores centrais: os trabalhadores da saúde e os usuários do SUS. O texto foca sobretudo os trabalhadores, afirmando que a reforma deve incorporá-los como sujeitos e não enquadrá-los com formas de controle. Essa é a primeira das funções que a noção de subjetividade vem responder: enfatizar a implicação subjetiva dos diferentes atores sociais no avanço ou retrocesso da reforma sanitária.

$\mathrm{O}$ texto tem duas inflexões. A primeira retoma a discussão mais antiga na Saúde Coletiva no uso da noção de ator social, proposta por Alain Touraine, na análise dos movimentos sociais. Sabemos que o sociólogo francês acopla essa noção à de sujeito: o sujeito é "o apelo à transformação do Si-mesmo em ator" 19 (p. 221), tornando-se fonte de "resistência ao poder social" 19. Temos aí o mais frequente uso da noção de sujeito na literatura da Saúde Coletiva, designando a dimensão de agente coletivo, ou ator, da mudança social. O uso dessa função está diretamente associado à primeira etapa de lutas do movimento sanitário, sendo, por conseguinte, a variável externa dessa dimensão do conceito: "aquela em que predominou a construção de sujeitos políticos capazes de formular e conduzir o processo da reforma sanitária" 18 (p. 750). Campos 11 utiliza de modo intercambiado as expressões ator e sujeito social.

A segunda inflexão, antecipando um debate que somente se tornaria prevalente alguns anos depois, aponta para a necessidade de complementar a dimensão macropolítica da luta com a dimensão micropolítica associando os conceitos de "revolução molecular de Guattari e de luta por uma nova civilização de Gramsci" 11 (p. 86). A proposta é de trabalhar concomitantemente processos coletivos e processos mais individualizados, mesmo que não necessariamente centrados em um indivíduo isolado.

A introdução de um autor do campo pós-estruturalista no debate do campo ocorre em um momento específico, após a obtenção da institucionalidade jurídico-legal do SUS na Constituição Federal de 1988 e das Leis nº 8.080 e nº. 8.142 de 1990. Essas vitórias permitiram ao movimento sanitário voltar sua atenção sobre as práticas de saúde, sobre o cotidiano da assistência. Paulatinamente, vai se tornando mais claro que o avanço da reforma sanitária depende da transformação da assistência. Um dos aportes 
conceituais que favorecem esse enfrentamento é uma concepção de subjetividade que associe processos de natureza mais coletiva, com processos de natureza mais individualizada e relacional. Não se trata de pensar a subjetividade como interioridade psicológica, intimidade privada, e muito menos um retorno ao indivíduo liberal. Busca-se reconhecer a dimensão política da subjetividade vivida de modo mais particular, em sua conexão com os processos macrossociais: “[é] na gestão do cotidiano que se constrói esta ou aquela subjetividade, sujeitos autônomos ou sujeitados" 11 (p. 94). Nesse aspecto, as contribuições dos autores pós-estruturalistas, como Guattari em seu trabalho com Deleuze e os estudos de Foucault sobre modos de subjetivação na década de 1980, mostram-se como ferramentas importantes e são utilizadas com frequência pelo movimento sanitário no Brasil. Ponderamos aqui que pós-estruturalismo é uma expressão estadunidense para classificar um conjunto de teóricos franceses que, baseados nas contribuições de Nietzsche, discutem, entre outros temas, novas noções de subjetividade, história, forças vitais, diferença e criação, mantendo proximidades e discordâncias com o estruturalismo francês. Ainda que os próprios autores citados recusem essa classificação, por não desejarem aderir a qualquer programa filosófico padrão, nós a utilizamos ao referirmo-nos a alguns autores presentes nos debates da Saúde Coletiva, especialmente Foucault, Deleuze e Guattari.

A institucionalização do SUS permitiu, ou mesmo exigiu, que o movimento sanitário voltasse sua atenção para outras dimensões fundamentais da reforma sanitária, sendo uma delas a prática de assistência. Ficava evidente que a criação do SUS e a ocupação de cargos de gestão em diferentes níveis feitas por militantes modificou certo arranjo institucional, "mas não necessariamente transformou as práticas dos serviços" 20 (p. 1413). Uma nova etapa de lutas precisava ser encetada pelo movimento: a luta pela transformação das práticas de atenção, o que abordaremos na sequência. Nessa próxima etapa, busca-se a noção de subjetividade, não apenas como designação da ação coletiva, mas como forma de entender o cotidiano da assistência.

\section{Segunda função: intersubjetividade no cuidado e na gestão}

Temos então a entrada de uma segunda função da noção de subjetividade no campo da Saúde Coletiva, como estratégia de problematizar a assistência como prática intersubjetiva 14 . Trata-se de defender antes de tudo que as práticas em saúde sejam sempre intersubjetivas, nas quais "profissionais de saúde se relacionem com sujeitos, e não com objetos” 20 (p. 1414). Essa discussão possui uma interface, associada a uma compreensão crescente entre vários autores da conexão necessária entre as práticas de cuidado e as práticas de gestão, e a preocupação de problematizar o tema da gestão em sua ligação com a subjetividade 9,21,22,23,24. Aqui, a variável externa em jogo é o reconhecimento de que a criação do aparato jurídico-institucional do SUS, per se, não transformou as práticas de cuidado e gestão no cotidiano, exigindo a construção de novas estratégias com intuito de atingir tal mudança.

Ayres 14 aponta que a categoria de "sujeito como o ser que produz a história”, a primeira função que esse conceito teve no debate, mostrou-se insuficiente para atender aos valores do SUS, especialmente o da integralidade das práticas. Segundo o autor, esse uso traz consigo dois núcleos de significação implícitos. O primeiro é a ideia de permanência ou "mesmidade", que reside neste sujeito identitário. O segundo é a ideia do sujeito histórico como produtor de progresso para a vida humana. Propõe então uma ampliação que enriqueça o uso da noção de sujeito:

"Uma conceitualização de subjetividade em que a ideia de permanência associada à dimensão identitária, seja substituída pela de contínua construção de identidades e a ideia de produção relacionada à dimensão transformadora, seja abarcada pela de sucesso prático [acentuando] o caráter imediatamente relacional e contingente de nossas identidades e historicidades como indivíduos e grupos" 14 (p. 65).

Sua proposta realça a dimensão relacional da subjetividade, rebatizada de intersubjetividade, como modo de contemplar a dimensão dialógica sempre presente nas práticas de saúde, quer reconheçamos ou não. Por isso, imersos na dimensão dialógica da existência, cabe aos profissionais de saúde criar pontes linguísticas entre o mundo tecnocientífico e o senso comum, no desenvolvimento de ações de cuidado. Além disso, as práticas de cuidado transcendem à ação de construir um objeto e intervir sobre ele, seja a doença ou mesmo o doente. Há que se considerar e construir projetos sustentáveis ampliados, que incluam a compreensão dos "projetos de felicidade, de sucesso prático de quem quer ser cuidado" 14 (p. 71).

Mattos 25 acentua alguns elementos históricos associados à segunda função rastreada na literatura, de considerar as práticas de assistência como necessariamente intersubjetivas. Ao analisar dois documentos produzidos pelo movimento sanitário para estimular debates com o Poder Legislativo, o primeiro em 1979 e o segundo em 
2006, o autor revela como o acento sobre a mudança das práticas só se efetivou tardiamente. $\mathrm{O}$ documento de 1979 subordinava a má qualidade das práticas de assistência ao modelo de política governamental em voga na época, tecnocrático e privatizante, pressupondo que a melhoria das práticas de assistência se daria em decorrência da transformação do modelo assistencial para outro descentralizado e democrático. Já o documento de 2006, O SUS para Valer: Universal, Humanizado e de Qualidade 26, defende uma mudança radical nas práticas como condição de garantia da legitimidade do SUS.

Portanto, temos uma nova ênfase nas estratégias do movimento sanitário. Conjuntamente com o prosseguimento da luta para a ampliação do acesso aos serviços públicos de saúde, ideia-força do início do movimento, busca-se transformar práticas de cuidado e de gestão em instituições de saúde. Nesse processo de transformação, Mattos focaliza o princípio da integralidade do cuidado como prática intersubjetiva, tese que já defendia em texto anterior 20; segundo ele, pouco enfatizada durante a luta pela construção do SUS.

Outro autor que apresenta essa preocupação com a mudança das práticas de cuidado e gestão em sua dimensão intersubjetiva é Merhy 12, com o aporte do conceito de "trabalho vivo em saú$d e$ " e em sua tipologia das diferentes tecnologias do trabalho em saúde, em mais uma aproximação de conceitos oriundos do marxismo com conceitos do pós-estruturalismo. O autor apresenta suas ideias como tendo sido engendradas em trabalhos de consultorias junto a diversos municípios, numa trajetória com trabalhadores e usuários do SUS, em seus modos de produzirem-se mutuamente "como uma máquina permanente de produções de subjetividades, de modos de sentir, de representar e de vivenciar necessidades" 12 (p. 72).

Merhy 12 classifica as tecnologias em saúde como: dura - equipamentos, insumos, estruturas organizacionais; leve-dura - saberes estruturados; leve - tecnologias relacionais tais como vínculo, acolhimento, autonomização, entre outras. As duas primeiras são mais capturadas pelo trabalho morto, mas as tecnologias leves, de "encontros de subjetividades", dele escapam permanentemente, constituindo-se como trabalho vivo em ato. Esses conceitos serão largamente utilizados, tanto em outros estudos quanto em propostas operacionais de mudanças de processos de trabalho em várias secretarias municipais de saúde no país, enfatizando a implementação de tecnologias de cuidado que acentuam a dimensão intersubjetiva das práticas de saúde. Seu trabalho acentua a necessária inter-relação entre "os modelos de atenção e os processos gerenciais", na medida em que as tecnologias do trabalho em saúde operam no espaço de gestão ${ }^{12}$.

Campos e Onocko-Campos têm enfatizado a indissociabilidade entre clínica e gestão para a produção de saúde, trabalhando nos últimos anos numa linha de pesquisa intitulada "gestão e subjetividade" 9,24,27. A proposta de cogestão 28, envolvendo o conjunto dos atores sociais ligados ao SUS, como estratégia de redistribuição de poder, tem sido retomada e debatida por vários pesquisadores e inspirado experiências locais e nacionais.

Atualizando várias discussões presentes na literatura, Guizardi \& Cavalcanti sugerem que o SUS não é apenas um sistema de saúde que oferece serviços, mas é também um campo de lutas do movimento sanitário, "sobretudo, como terreno de interação e produção de sujeitos em luta por uma nova sociedade" 21 (p. 634). É nesse terreno que se pode mobilizar os sujeitos na luta pelo SUS. Os autores desenvolvem no artigo uma análise indicando a centralidade da cogestão na saúde, como estratégia inovadora de redistribuição de poder entre os diferentes sujeitos envolvidos na promoção de avanços no SUS.

A Política Nacional de Humanização (PNH), estabelecida durante a permanência de Gastão Wagner de Souza Campos na secretaria executiva do Ministério da Saúde, configurou como um de seus três princípios, a "indissociabilidade entre atenção e gestão”, entendida como associação inseparável entre os modos de cuidar e os modos de gerir, entre clínica e política, e entre produção de saúde e produção de sujeitos 28 . A PNH apresenta-se como uma das tentativas mais marcantes de concretização dessa segunda função do uso da noção de subjetividade na saúde.

No esforço de distinguir entre funções que operam com tanta proximidade, podemos estabelecer uma distinção entre as duas já apresentadas. Se a primeira função opera essencialmente no plano macropolítico, a segunda agrega o plano estratégico, buscando transformar as práticas de cuidado e de gestão, entendidas como portadoras de uma dimensão intersubjetiva, de modo a qualificar a assistência à saúde.

Os teóricos convocados para sustentar essa função que intenta problematizar a transformação das práticas de assistência possuem um leque mais extenso em suas filiações teóricoconceituais, com nítido deslocamento, relativamente à função anterior, das ciências sociais para as ciências humanas. Temos aqui muitos autores-filósofos de vários matizes como Habermans (teoria crítica); Foucault, Deleuze e Guattari (pós-estruturalismo); Heidegger, Gadamer (hermenêutica), entre outros, além de autores da 
psicanálise como Freud eWinnicott. Canguilhem é outro autor bastante referido.

Assim, torna-se mais complexo aferir os princípios da variável interna e de consistência sistemática dessa função, mas podemos indicar alguns, com a ressalva de que nem sempre abarcam o conjunto de autores. O primeiro princípio, já indicado anteriormente, é que são autores que permitem uma reflexão que articule a dimensão individual e a coletiva da subjetividade nos processos de cuidado e gestão. O segundo é que a maioria deles traz uma preocupação política na reflexão, elemento esse que está presente nas três funções que nossa investigação identificou. Finalmente, é possível encontrar nesses autores formas de pensar o cuidado e a gestão em saúde de modo mais extenso e intenso, menos dependente de uma perspectiva exclusivamente biomédica.

\section{Terceira função: a produção de autonomia}

Uma terceira função que demanda o conceito de subjetividade é a discussão da temática da produção de autonomia nos indivíduos e coletivos envolvidos nas ações de saúde, dentro do entendimento de que é objetivo do trabalho em saúde, tanto a própria produção em saúde, quanto a "construção de capacidade de reflexão e de ação autônoma para os sujeitos envolvidos nesse processo" 27 (p. 669). Para a abordagem da temática é utilizado um conjunto de expressões para designar essa função, tais como participação, protagonismo, empowerment ou empoderamento, entre outros. Na busca feita na SciELO, por ocasião do primeiro levantamento realizado, quando associados ao descritor saúde, o termo participação apresentou o maior número de entradas, 678, seguido por autonomia com 214 , empoderamento com 26 e protagonismo com 20 referências.

Essa temática, na dimensão histórica de seu surgimento, antecede e atravessa as duas primeiras funções do uso da noção de subjetividade estudadas. Numa abordagem histórica das políticas de educação em saúde, Gastaldo ${ }^{29}$ ressalta que a ideia de participação está presente nos documentos do Ministério da Saúde desde 1981, ainda no Regime Militar na gestão do Governo Figueiredo, com uma linguagem e referências influenciadas pela obra de Paulo Freire. Há também forte influência dos organismos internacionais que enfatizam a participação em propostas de extensão de cobertura de assistência à saúde em países latino-americanos na década de 1960 . No entanto, a inclusão explícita da noção de subjetividade nessa discussão é tão recente quanto nas duas primeiras funções analisadas. Apesar de a expressão participação ter um uso fortemente consolidado nas políticas públicas e nas políticas de saúde, preferimos jogar um maior foco sobre a ideia de autonomia. Esta expressa melhor a indicação da Política Nacional de Promoção da Saúde (PNPS), direção principal do escopo geral da pesquisa em andamento, já que atesta que "a produção de saúde torna-se indissociável da produção de subjetividades mais ativas, críticas, envolvidas e solidárias" 30 (p. 13).

Reconhecemos que as diversas expressões utilizadas, apesar de não serem sinônimas, circunscrevem certo campo de debates com várias intercessões. No âmbito dos debates na promoção da saúde, essa temática é bastante presente. Além disso, tal como as duas anteriormente discutidas, ela mantém forte nexo com as demais. Em contrapartida, esse uso da noção de subjetividade, associada às de autonomia e participação, é a que mais provoca dissensões e debates, tanto sobre seu valor quanto sobre seu "mau uso".

Por vezes, as ideias de empowerment e participação são criticadas como estratégias de fundo moralizador e autoritário, para promover a saúde sob o controle do Estado. Ainda que se reconheça uma dimensão de politização dessas noções, elas são criticadas por produzirem "uma nova forma de tutela sobre a maioria da população” 31 (p. 15), atendendo às diretrizes da Organização Mundial da Saúde e do Banco Mundial. Stotz \& Araújo 31 entendem empowerment como uma abordagem para melhora das condições de vida de grupos mais vulneráveis. Contudo, apontam o paradoxo que põe, de um lado, os empoderadores, em geral o Estado e seus técnicos, e, de outro, os empoderados, em geral os segmentos vulneráveis da população. Nessa perspectiva, ignora-se que ambos os lados têm trajetória e interesses próprios. Os autores convidam ao seguinte questionamento: quem garante que os segmentos que detêm maior poder estão dispostos a se autolimitarem?

O mesmo paradoxo é exposto por Deborah Lupton, quando indica que o ideário da promoção da saúde porta uma discursividade semelhante à dos movimentos sociais, numa retórica que desafia a regulação do Estado. Mas, por outro lado, suas origens residem no Estado, na gestão da saúde pública, "ao invés de [o] desafiarem diretamente" 32 (p. 61), como os demais movimentos sociais.

Há uma crítica à associação de algumas dessas noções à ênfase de mudança comportamental, dos "estilos de vida", produzida pelo Relatório Lalonde no Canadá. A autonomia, nesse caso, passa a equivaler à responsabilização dos pacientes pelo próprio adoecimento, a "culpabilização das vítimas (blaming the victims)” 33. Au- 
tonomia, então, equivaleria a delegar aos indivíduos a responsabilidade pelos próprios cuidados com a saúde. Carvalho 33 ainda distingue dois tipos de empoderamento, um de cunho "psicológico", que busca fortalecer a autoestima e mecanismos de autoajuda e solidariedade, e outro de cunho "comunitário", que visa ao aumento da eficácia política em grupos e coletivos. Enquanto o primeiro pode produzir, no máximo, uma "autonomia regulada", o segundo pode produzir estratégias políticas promotoras de uma autonomia mais plena. $\mathrm{O}$ autor conclui seu artigo dizendo ser um dos desafios da promoção da saúde a "produção de sujeitos autônomos e socialmente responsáveis" 33 (p. 677). Temos presente, num mesmo estudo, dois sentidos de autonomia, uma regulada e outra politicamente eficaz.

Movimento similar de discriminação entre duas modalidades de autonomia aparece em outros autores, que diferenciam uma autonomia de cunho neoliberal na qual o sujeito é senhor de si mesmo, independente de todo o resto, de uma compreensão da autonomia como ampliação da "capacidade das pessoas de agirem sobre os determinantes de sua saúde" 34 (p. 2120).

Percebemos, portanto, que a terceira função, a da noção de subjetividade associada à autonomia, se constitui como um terreno marcado por tensões e controvérsias. Além disso, abrange uma variedade de áreas, tais como a relação médico-paciente ${ }^{35,36}$, a educação em saúde ${ }^{37}$, a gestão em saúde 24 , as estratégias de promoção da saúde 34,38 , os modos de vida 39 , entre outros. Uma análise extensa dessas variações foge ao escopo deste artigo. Interessa-nos, aqui, entender como a noção de autonomia e seus correlatos, ligados à de subjetividade, é estabelecida na Saúde Coletiva e na promoção da saúde.

Para se afastar do uso de autonomia associada a uma "subjetividade política da era neoliberal" atomizada, consumista, independente 31 , diversos estudiosos constroem uma abordagem mais complexa da questão, agregando a experiência individual e a coletiva: "não se pode falar de indivíduo como isolado do coletivo" 36 (p. 73). Nesse sentido, nas palavras de Onocko-Campos \& Campos 27 (p. 670), “autonomia poderia ser traduzida em um processo de co-constituição de maior capacidade dos sujeitos de compreenderem e agirem sobre si mesmos e sobre o contexto conforme objetivos democraticamente estabelecidos".

Os mesmos autores ainda apontam que a autonomia não se traduz como um estado estático, obtido de modo definitivo, mas como um processo dinâmico, cuja perenidade não está garantida. Ela é "uma forma relativa, em gradientes passíveis de terem seus limites sempre tensionados, mudados" 27 (p. 674). Além disso, à medida que estamos, em última instância, lidando com coletivos, ela se expressa também na capacidade dos sujeitos de lidarem com sua rede de dependências. Consequentemente, inclui-se o conjunto de serviços de saúde e redes sociais a que ele tem acesso, fortalecendo a coconstituição de capacidades.

A PNPS enfatiza esse aspecto ao valorizar a produção de subjetividades autônomas, contrapondo-se a uma concepção neoliberal de autonomia como livre escolha individual, própria do ideário neoliberal de mercado 34 . A literatura estudada também se afasta de identificar autonomia como uma vivência puramente psicológica ou associada à individualidade neoliberal. Ao contrário, dedica-se a entendê-la como um processo complexo que envolve aspectos biológicos, subjetivos, socioculturais, econômicos, coletivos 40 .

O leque de teóricos que compõem essa terceira função repete parcialmente o da função anterior. Ambas as funções deslocam o foco sociológico de fundo marxista para um diálogo mais ampliado com o campo das ciências humanas, associando processos individuais e coletivos da experiência subjetiva.

\section{Alguns entrelaçamentos entre as funções do conceito de subjetividade na Saúde Coletiva}

Essas três funções rastreadas na primeira etapa da pesquisa permitem analisar alguns usos da noção de subjetividade no campo da Saúde Coletiva em múltiplos movimentos. Todas elas - a construção política de atores sociais para a reforma, a intersubjetividade no cuidado e na gestão e a produção de autonomia - têm conexões evidentes. As três apontam na direção de viabilizar a plena realização dos princípios do SUS, reconhecendo o caráter eminentemente político desse projeto. Logo, não se trata aqui de uma subjetividade entendida como interioridade psicológica, mas da produção de subjetividades atravessadas pela dimensão política. Indicam também uma discussão que se desloca de um enquadre exclusivamente macropolítico, para construir uma associação com o âmbito micropolítico.

A noção de micropolítica deve ser aqui nuançada mediante a referência dos teóricos que mais a adotam. Deleuze \& Guattari ${ }^{41}$ consideram que o micropolítico não designa uma questão de tamanho, como uma apreensão inicial pode sugerir, mas de natureza de fluxos. Se o macropolítico opera por um modo de organização territorializante, com codificações binárias - como entre profissionais e usuários, estado e sociedade civil, 
saber científico e saber popular, entre outros - e segmentadas, a micropolítica opera pela desterritorialização dos códigos, pela produção intensiva de percepções, afetos, conversas. Mesmo se o molecular da micropolítica atua no detalhe, passando por pequenos grupos, "nem por isso ele é menos coextensivo a todo o campo social, tanto quanto a organização molar" 41 (p. 93). Deleuze \& Guattari 41 exemplificam o Maio de 68 francês como possuidor dessa condição. Mas podemos indicar que os movimentos sociais em geral, à proporção que transformam as classes sociais segmentadas em massas intensivas, operam molecularmente por micropolíticas.

Destarte, “toda política é ao mesmo tempo micropolítica e macropolítica” 41 (p. 90). Ambas são composições indissociáveis de toda política e sua distinção é apenas por serem portadoras de modos de operação diferentes, embora sempre se sustentem uma na outra. Nesse sentido, a reforma sanitária não pode esgotar sua ação no nível macropolítico de construção do aparato jurídico-institucional. Deve considerar que o próprio movimento para sua construção é portador de um índice micropolítico do movimento social, que misturou classes sociais (intelectualidade acadêmica e classe popular) numa massa orgânica, e pressionou pela mudança macropolítica. A VIII Conferência Nacional de Saúde foi um grande encontro, ao mesmo tempo, macro e micropolítico, catalisador desse processo de mudanças. Essa perspectiva de leitura dos processos políticos pela inter-relação entre as dimensões macro e micro, pode trazer contribuições à discussão, visto que a subjetividade também comporta dimensões segmentadas e dimensões flexíveis.

“A política opera por macrodecisões e escolhas binárias, interesses binarizados; mas o domínio do decidivel permanece estreito. E a decisão politica mergulha necessariamente num universo de microdeterminações, atrações e desejos, que se deve pressentir ou avaliar de um outro modo. [...] Boa ou má, a política e seus julgamentos são sempre molares, mas é o molecular, com suas apreciações, que a 'faz"' 41 (p. 102).

Outro bom exemplo da relação entre essas duas dimensões no contexto do SUS é a Estratégia Saúde da Família como eixo macropolítico reorientador do SUS. Sua institucionalização e fortalecimento pelo incentivo de financiamento junto aos municípios têm produzido importantes experiências locais de revisão das práticas de atenção pelo diálogo formalmente instaurado com as equipes, tendo no agente comunitário de saúde um ator social chave. Essa dimensão micropolítica de diálogo intersetorial com as comunidades, embaralha e desterritorializa os tradi- cionais códigos técnico-profissionais e convoca todos a construírem novos planos de intervenção e invenção de modos de vida e coexistência que compartilhem o saber-fazer profissional com o saber-fazer das pessoas e coletivos ${ }^{3}$. Além disso, a proposta da cogestão, abordada anteriormente, na medida em que faculta novos arranjos nas relações de poder, embaraçando códigos e hierarquias, também é portadora de uma vocação micropolítica.

Nossa pesquisa teve for foco o debate brasileiro em torno da noção de subjetividade na saúde. Não obstante, vale mencionar que essa discussão acontece em outros países. Podemos citar, entre outros, os trabalhos do argentino, exilado no México, Eduardo Menéndez ${ }^{42}$, do inglês Nikolas Rose 43, ou dos australianos Alan Petersen e Deborah Lupton 44 . Todavia, foge ao escopo da presente investigação explorar as aproximações e diferenças entre esses usos, mesmo reconhecendo que esse é um interessante caminho a ser trilhado.

\section{Considerações finais}

Em suas variáveis externas, as três funções se estabelecem com processos de construção de estratégias micro e macropolíticas em prol da consolidação do SUS. Compartilham, destarte, de movimentos para o desenho e redesenho das políticas públicas e práticas de saúde.

Podemos entender que o uso da noção de subjetividade na Saúde Coletiva realça o vínculo entre dimensões materiais e dimensões subjetivas nas práticas em saúde, intentando construir pontes entre experiências coletivas e experiências individuais. Tal associação aparece de modo incisivo no documento da PNPS, ficando evidente pela presença, em oito ocasiões, da expressão “sujeitos e coletividades" 30. Ressalta-se, assim, a busca da necessária articulação entre as dimensões coletivas e individuais nas práticas de gestão e cuidado do SUS.

No aspecto da construção teórica, percebe-se a ampliação do diálogo interdisciplinar no campo da Saúde Coletiva, particularmente na discussão da temática da subjetividade em suas diversas acepções. Tendo um aporte inicial centrado na tradição do materialismo histórico e nas ciências sociais, a discussão amplia suas referências para as ciências humanas, com destaque para a filosofia, em diferentes escolas de pensamento, e para a psicanálise.

A opção feita de trabalharmos a análise dos textos privilegiando certa perspectiva pós-estruturalista nos pareceu instigante para a discussão dos dados por possibilitar o deslocamento do 
foco de um debate epistemológico para a análise da relação entre conceitos e a história social do SUS. Isso nos permitiu evitar uma análise exclusivamente internalista dos textos, para realçar as condições históricas e sociais da emergência desse debate na Saúde Coletiva. Também permitiu problematizar o debate em seus diferentes níveis de operação, seja o macropolítico, seja o micropolítico. Não objetivamos avaliar a relevância maior ou menor das diferentes escolas teóricas que foram utilizadas pelos autores dos textos estudados, mas entender as funções dessa utilização e sua conexão com problemas que se

\section{Resumo}

Analisa-se o uso da noção de subjetividade no campo da saúde coletiva associada às condições históricas e institucionais que o demandaram. A busca em periódicos específicos da área e livros de referência constituiu-se como estratégia metodológica central. Identificamos três funções no uso do conceito de subjetividade, associando-as primariamente às suas variáveis externas (trajetória do movimento sanitário e institucionalização do SUS), e secundariamente às variáveis internas (lógica do campo teórico-conceitual). As funções identificadas discutem a subjetividade (1) como elemento para se pensar a ação social de sujeitos políticos engajados no projeto da Reforma Sanitária; (2) como estratégia de problematizar o cuidado e a gestão como práticas intersubjetivas; (3) como substrato para a produção de autonomia nos indivíduos e coletivos. Em suas variáveis externas, as três funções se estabelecem como processos de construção de estratégias micro e macropolíticas em prol da consolidação do SUS.

Domínios Científicos; Saúde Pública; Sistema Único de Saúde; Revisão colocaram em diferentes momentos da reforma sanitária. A despeito dessa escolha, entendemos que a pluralidade teórica e disciplinar da Saúde Coletiva é um de seus atributos mais fecundos.

As três funções aqui analisadas, apesar de possuírem surgimentos historicamente não coincidentes, não são excludentes. Pelo contrário, a ação social dos sujeitos coletivos, a atenção como prática intersubjetiva e a autonomia subjetiva e material como alvo das ações de saúde se estabelecem como dimensões associadas e fundamentais ao avanço de nossa, ainda inconclusa, reforma sanitária.

\section{Colaboradores}

J. L. Ferreira Neto participou de todas as etapas de produção do artigo: produção e interpretação dos dados, concepção, delineamento, redação e revisão do artigo. L. Kind contribuiu para a concepção, delineamento, redação e revisão crítica do artigo. A. B. Pereira participou na interpretação dos dados, concepção e delineamento do artigo, e aprovação da versão final. M. C. C. Rezende participou na interpretação dos dados, concepção e delineamento do artigo, e aprovação da versão final. M. L. Fernandes participou na interpretação dos dados, concepção e delineamento do artigo, e aprovação da versão final.

\section{Agradecimentos}

Ao Conselho Nacional de Desenvolvimento Científico e Tecnológico (CNPq) e à Fundação de Amparo à Pesquisa do Estado de Minas Gerais (FAPEMIG). 


\section{Referências}

1. Arouca S. O dilema preventivista: contribuição para a compreensão e crítica da medicina preventiva. São Paulo: Editora Unesp/Rio de Janeiro: Editora Fiocruz; 2003.

2. Rodrigues HBC. Sobre as histórias das práticas grupais: explorações quanto a um intrincado problema. In: Mancebo D, Jacó-Velela A, organizadores. Psicologia social: abordagens sócio-históricas e desafios contemporâneos. 2a Ed. Rio de Janeiro: Eduerj; 2004. p. 113-67.

3. Foucault M. Microfísica do poder. Rio de Janeiro: Graal; 1979.

4. Deleuze G. Deux regimes de fous. Paris: Les Éditions Minuit; 2003.

5. Minayo MCS. O desafio do conhecimento. 6a Ed. São Paulo: Editora Hucitec/Rio de Janeiro: ABRASCO; 1999.

6. Alvarez J, Passos E. Pista 7: cartografar é habitar um território existencial. In: Passos E, Kastrup V, Escóssia L, organizadores. Pistas do método da cartografia. Porto Alegre: Sulina; 2009. p. 131-49.

7. Foucault M. A arqueologia do saber. 3 a Ed. Rio de Janeiro: Forense Universitária; 1987.

8. Campos GSW. Saúde pública e saúde coletiva: campo e núcleo de saberes e práticas. Ciênc Saúde Coletiva 2000; 5:219-30.

9. Onocko-Campos R. O encontro trabalhadorusuário na atenção à saúde: uma contribuição da narrativa psicanalítica ao tema do sujeito na saúde coletiva. Ciênc Saúde Coletiva 2005; 10:573-83.

10. Minayo MCS. Editorial. Ciênc Saúde Coletiva 2001; 6:4-5.

11. Campos GSW. Sobre a peleja dos sujeitos da reforma ou da reforma dos sujeitos em peleja. Saúde Soc 1992; 1:79-95.

12. Merhy EE. Em busca do tempo perdido: a micropolítica do trabalho vivo em saúde. In: Merhy EE, Onocko R, organizadores. Agir em saúde: um desafio para o público. São Paulo: Editora Hucitec; 1997. p. 71-112.

13. Minayo MCS. Estrutura e sujeito, determinismo e protagonismo histórico: uma reflexão sobre a práxis da saúde coletiva. Ciênc Saúde Coletiva 2001; 6:7-19.

14. Ayres JRCM. Sujeito, intersubjetividade e práticas de saúde. Ciênc Saúde Coletiva 2001; 6:63-72.

15. Paim JS. Reforma Sanitária Brasileira: contribuições para a compreensão e crítica. Salvador: EDUFBA/Rio de Janeiro: Editora Fiocruz; 2008.

16. Bosi MLM. Cidadania, participação popular e saúde na visão dos profissionais do setor: um estudo de caso na rede pública de serviços. Cad Saúde Pública 1994; 10:446-56.

17. Carvalho AI. Da saúde pública às políticas saudáveis - saúde e cidadania na pós-modernidade. Ciênc Saúde Coletiva 1996; 1:104-21.

18. Fleury S. Reforma sanitária brasileira: dilemas entre o instituinte e o instituído. Ciênc Saúde Coletiva $2009 ; 14: 743-52$.

19. Touraine A. Crítica da modernidade. Petrópolis: Editora Vozes; 1994.

20. Mattos RA. A integralidade na prática (ou sobre a prática da integralidade). Cad Saúde Pública 2004; 20:1141-6.
21. Guizardi FL, Cavalcanti FO. A gestão em saúde: nexos entre o cenário institucional e a participação política no SUS. Interface Comum Saúde Educ 2010; 14:633-45.

22. Abrahão AL, Martins CM, Geisler A. O sujeito na literatura acadêmica sobre gestão em saúde: notas para a questão da autonomia. Ciênc Saúde Coletiva $2008 ; 13: 247-57$.

23. Azevedo CS, Braga Neto FCB, Sá MC. Indivíduo e mudança nas organizações. Cad Saúde Pública 2002; 18:235-47.

24. Campos GWS. Um método para análise e co-gestão de coletivos. São Paulo: Editora Hucitec; 2000.

25. Mattos RA. Princípios do Sistema Único de Saúde (SUS) e a humanização das práticas de saúde. Interface Comun Saúde Educ 2009; 13 Suppl 1: 771-80.

26. Fórum da Reforma Sanitária. Saúde Debate 2006; 29:385-96.

27. Onocko-Campos R, Campos GWS. Co-construção de autonomia: o sujeito em questão. In: Campos GWS, Minayo MC, Akerman M, Drumond Júnior M, Carvalho YM, organizadores. Tratado de saúde coletiva. São Paulo: Editora Hucitec/Rio de Janeiro: Editora Fiocruz; 2006. p. 669-88.

28. Ministério da Saúde. Humaniza SUS: documento básico para gestores e trabalhadores do SUS. Brasília: Ministério da Saúde; 2004.

29. Gastaldo D. É a educação em saúde "saudável"? Repensando a educação em saúde através do conceito de biopoder. Educação \& Realidade 1997; 22:147-67.

30. Ministério da Saúde. Política Nacional de Promoção de Saúde. Brasília: Ministério da Saúde; 2006.

31. Stotz EN, Araújo JWG. Promoção da saúde e cultura política: a reconstrução do consenso. Saúde Soc 2004; 13:5-19.

32. Lupton D. The imperative of health: public health and regulated body. London: Sage; 1995.

33. Carvalho SR. As contradições da promoção à saúde em relação à produção de sujeitos e a mudança social. Ciênc Saúde Coletiva 2004; 9:669-78.

34. Fleury-Teixeira P, Vaz FAC, Campos FCC, Álvares J, Aguiar RAT, Oliveira VA. Autonomia como categoria central no conceito de promoção da saúde. Ciênc Saúde Coletiva 2008; 13 Suppl 2:2115-22.

35. Martins A. Biopolítica: o poder médico e a autonomia do paciente em uma nova concepção de saúde. Interface Comun Saúde Educ 2004; 8:21-32.

36. Soares JCR, Camargo Jr. KR. A autonomia do paciente no processo terapêutico como valor para a saúde. Interface Comun Saúde Educ 2007; 11:65-78.

37. Smeke EL, Oliveira NL. Educação em saúde e concepções de sujeito. In: Vasconcelos EM, organizador. A saúde nas palavras e nos gestos: reflexões da rede de educação popular e saúde. São Paulo: Editora Hucitec; 2001. p. 115-36.

38. Carvalho SR, Gastaldo D. Promoção à saúde e empoderamento: uma reflexão a partir das perspectivas crítico-social e pós-estruturalista. Ciênc Saúde Coletiva 2008; 13 Suppl 2:2029-40.

39. Nogueira RP. A saúde pelo avesso. Natal: Seminare; 2003. 
40. Figueiredo MD, Furlan PG. O subjetivo e o sociocultural na produção de saúde e autonomia. In: Campos GWS, Guerreiro AVP, organizadores. Manual de práticas de atenção básica: saúde ampliada e compartilhada. São Paulo: Editora Hucitec; 2008. p. 154-68.

41. Deleuze G, Guattari F. Mil platôs. v. 3. Rio de Janeiro: Editora 34; 1996.

42. Menendéz E. Sujeitos, saberes e estruturas: uma introdução ao enfoque relacional no estudo da saúde coletiva. São Paulo: Editora Hucitec; 2009.
43. Rose N. The politics of life itself: biomedicine, power, and subjectivity in the Twenty-First Century. Princeton: Princeton University Press; 2007.

44. Petersen A, Lupton D. The new public health: health and self in the age of risk. London: Sage; 1996.

Recebido em 02/Out/2010

Versão final reapresentada em 29/Mar/2011

Aprovado em 29/Mar/2011 